\title{
Qualitative and Morphometric Characters of Aseel Male Chicken
}

\author{
R. Richard Churchil*, J. Jamima, Yadav Sunil Machindra, \\ P. Kanagaraju and G. Srinivasan
}

Department of Poultry Science, Madras Veterinary College, Tamil Nadu Veterinary and Animal Sciences University, Chennai-600 007, India

*Corresponding author

\section{A B S T R A C T}

\begin{tabular}{|l|}
\hline K e y w o r d s \\
Aseel, Indigenous, \\
Qualitative, \\
Biometry, \\
Morphology
\end{tabular}

\section{Introduction}

Aseel is one of the important chicken breed of India and is well known for its pugnacity, majestic gait, agility, high stamina and dodged fighting qualities (Singh, 2001). To increase the productivity of backyard and rural farming, improved or exotic varieties are being introduced in rural areas or in their breeding traits leading to a dilution of genetic purity of the breeds or a complete replacement of the native germplasm; hence, these breeds are under threat of extinction (Singh, 2009). The studies on indigenous breeds is scanty barring a very few reports (Kumar et al., 2013; Kumar et al, 2016; Rajkumar et al., 2017).
Therefore, the present study was carried out with the aim to record the qualitative characters and biometric measurements of Aseel breed of chicken.

\section{Materials and Methods}

The phenotypic and metric characters were studied from Aseel breed of chicken $(n=5)$ reared at department of poultry science, madras veterinary college, Chennai. The birds were 22 weeks of age at the time of study. The phenotypic characters were recorded by physical examination and the characters studied were skin colour, shank colour, ear lobe colour, eye colour, comb type, comb 
colour, comb position, presence of wattle and beak colour.

The body weight was measured using electronic bird weighing machine with the accuracy of $10 \mathrm{gm}$. The beak length was measured using vernier calliper with the accuracy of $0.1 \mathrm{~cm}$. Comb height to the accuracy of $0.1 \mathrm{~cm}$ from the base to tip of the spikes measured using vernier calliper. Shank length and spur length were also recorded with vernier calliper with the accuracy of $0.1 \mathrm{~cm}$. Girth of the body was measured at the point of keel bone and wing span by extending the wing when the bird was in standing posture was measured using measuring tape with the accuracy of $0.5 \mathrm{~cm}$. The length of keel bone from the point to the tip was measured with the help of vernier calliper with accuracy of $0.1 \mathrm{~cm}$. Breast angle was also measured at the point of keel bone. Height of the bird was measured up to the tip of the comb when bird was in normal standing posture. Body length from the tip of the beak to the tip of tail was measured after restraining the bird on table and extending the neck straight.

The data so collected was entered in Microsoft excel worksheet and the mean and standard error were calculated.

\section{Results and Discussion}

The frequency of different qualitative characters observed in this study is given in Table 1. The skin colour was yellow (100\%) in all the birds. However, a much contrasting finding of white skin colour in $90 \%$ of the birds was reported by (Rajkumar et al., 2017). (Negassa et al., 2014) observed the predominance of yellow skin in a study on phenotypic characterization of indigenous chicken of Ethiopia. The shank colour was also yellow (100\%) in all the birds subjected to this study. However, three shank colours of yellow (65\%), black (19\%) and white (16\%) has been reported in Aseel chicken by (Rajkumar et al., 2017). On the other hand (Dana et al., 2010) recorded yellow (60\%), white (28\%) and black (12\%) in the indigenous chicken population of Ethiopia. In this study, the authors observed two ear lobe colours namely red $(60 \%)$ and pinkish red (40\%). (Rajkumar et al., 2017) also recorded high proportion of $92 \%$ of red ear lobe in Aseel chicken. In Ethiopia the indigenous chicken population had predominately red $(52 \%)$ or white $(40 \%)$ ear lobes (Dana et al., 2010). The eye colour was yellow (100\%) in all the birds of this study. However in contrast to this (Rajkumar et al., 2017) reported black eye colour predominantly (99\%) in Aseel chicken.

Eighty per cent of the birds in this study had pea comb and remaining $20 \%$ had rose comb. A similar observation of $92 \%$ of pea comb was reported earlier in Aseel chicken (Rajkumar et al., 2017). The comb colour was red $(100 \%)$ in this study, which was in close agreement with the findings of (Rajkumar et al., 2017) who reported $82 \%$ dark red, $11 \%$ medium red and $7 \%$ pale red comb in Aseel chicken. All the birds examined in this study had erect $(100 \%)$ comb position. The wattles was absent in all the birds subjected for observations. However (Rajkumar et al., 2017) reported the presence of wattle in $72 \%$ of the birds. The beak colour was brownish yellow $(60 \%)$ or blackish yellow $(40 \%)$ in the present study. Similarly a highly predominant yellow beak (95\%) has been reported earlier by (Rajkumar et al., 2012) in Aseel breed of chicken.

The results of biometric measurements of adult Aseel males subjected in this study are presented in Table 2. The body weight of adult Aseel chicken at the age of 22 weeks was 1.87 $\mathrm{kg}$ with the values ranging from 1.75 to 1.95 $\mathrm{kg}$. However the indigenous chicken population in Ethiopia had comparatively 
lower body weight ranging from 1.29 to 1.69 $\mathrm{kg}$ (Bekele et al., 2015), 1.37 to 1.40
(Negassa et al., 2014) and 1.41 to $1.70 \mathrm{~kg}$ (Dana et al., 2010).

Table.1 Qualitative characters of Aseel male chicken

\begin{tabular}{|c|c|c|}
\hline Sr. No. & Parameter & Frequency \\
\hline \multirow[t]{2}{*}{1.} & Skin colour & \\
\hline & a) Yellow & 100 \\
\hline \multirow[t]{2}{*}{2.} & Shank colour & \\
\hline & a) Yellow & 100 \\
\hline \multirow[t]{3}{*}{3.} & Ear lobe colour & \\
\hline & a) $\operatorname{Red}$ & 60 \\
\hline & b) Pinkish red & 40 \\
\hline \multirow[t]{2}{*}{4.} & Eye colour & \\
\hline & a) Yellow & 100 \\
\hline \multirow[t]{3}{*}{5.} & Comb type & \\
\hline & a) $\mathrm{Pea}$ & 80 \\
\hline & b) Rose & 20 \\
\hline \multirow[t]{2}{*}{6.} & Comb colour & \\
\hline & a) Red & 100 \\
\hline \multirow[t]{2}{*}{7.} & Comb position & \\
\hline & a) Erect & 100 \\
\hline 8. & Presence of wattle & 0 \\
\hline \multirow[t]{3}{*}{9.} & Beak colour & \\
\hline & a) Brownish yellow & 60 \\
\hline & b) Blackish yellow & 40 \\
\hline
\end{tabular}

Table.2 The biometrical value of Aseel male chicken

\begin{tabular}{|c|l|l|l|}
\hline Sr. No & \multicolumn{1}{|c|}{ Parameter } & Range & Mean \pm SE \\
\hline $\mathbf{1 .}$ & Body Weight $(\mathrm{Kg})$ & 1.75 to 1.95 & $1.87 \pm 0.03$ \\
\hline $\mathbf{2 .}$ & Beak length $(\mathrm{cm})$ & 2.80 to 3.00 & $2.92 \pm 0.05$ \\
\hline $\mathbf{3 .}$ & Comb height $(\mathrm{cm})$ & 0.50 to 1.40 & $0.96 \pm 0.17$ \\
\hline $\mathbf{4 .}$ & Shank length $(\mathrm{cm})$ & 7.20 to 9.00 & $7.84 \pm 0.32$ \\
\hline $\mathbf{5 .}$ & Spur length $(\mathrm{cm})$ & 2.00 to 2.50 & $2.10 \pm 0.10$ \\
\hline $\mathbf{6 .}$ & Body girth $(\mathrm{cm})$ & 29.0 to 38.0 & $31.60 \pm 1.63$ \\
\hline $\mathbf{7 .}$ & Wing span $(\mathrm{cm})$ & 68.0 to 79.0 & $75.00 \pm 1.95$ \\
\hline $\mathbf{8 .}$ & Keel bone length $(\mathrm{cm})$ & 11.5 to 13.3 & $12.52 \pm 0.33$ \\
\hline $\mathbf{9 .}$ & Breast angle $($ Degree $)$ & 30.0 to 33.0 & $30.80 \pm 0.58$ \\
\hline $\mathbf{1 0 .}$ & Height of bird $(\mathrm{cm})$ & 42.0 to 50.0 & $44.70 \pm 1.41$ \\
\hline $\mathbf{1 1 .}$ & Body length $(\mathrm{cm})$ & 49.0 to 60.0 & $53.80 \pm 1.93$ \\
\hline
\end{tabular}

The mean beak length was $2.92 \mathrm{~cm}$ ranging from 2.80 to $3.00 \mathrm{~cm}$ which was slightly higher than the beak length of indigenous chicken of Western Ethiopia $(2.11 \mathrm{~cm})$ 
(Bekele et al., 2015). The comb height is rudimentary in Aseel chicken with the height ranging from 0.50 to $1.40 \mathrm{~cm}$ with the average of $0.96 \mathrm{~cm}$. However in other indigenous chicken, the comb height reported is ranging from 1.99 to $2.27 \mathrm{~cm}$ as reported by the (Bekele et al., 2015) in south western Ethiopia

The shank length was $7.84 \mathrm{~cm}$ ranging from 7.20 to $0.00 \mathrm{~cm}$ in the adult Aseel males in this study. A similar shank length of 9.98 to $10.45 \mathrm{~cm}$ (Bekele et al., 2015), $9.10 \mathrm{~cm}$ (Dana et al., 2010) and 7.37 to $7.5 \mathrm{~cm}$ (Negassa et al., 2014) reported in indigenous chicken population of Ethiopia. The spur length of Aseel chicken at the age of 22 week was 2.10 $\mathrm{cm}$ with the values ranging from 2.00 to 2.50 $\mathrm{cm}$ among birds. The body girth measured at the point of keel bone was ranging between 29.00 and $38.00 \mathrm{~cm}$ with the mean value of $31.60 \mathrm{~cm}$. The wing span measured between the tips of wings at extended position was $75.00 \mathrm{~cm}$.

The length of keel bone measured from the point to the tip was $12.52 \mathrm{~cm}$ in Aseel birds. A similar keel length of 12.02 was reported in South-bench Ethiopian indigenous chicken (Bekele et al., 2015). However, a lower value of $9.7 \mathrm{~cm}$ was reported in Lowland indigenous chickens of Ethiopia. The breast angle measured at the point of keel bone was 30.80 degree in Aseel males at 22 weeks of age in this study. However a higher breast angle of 46.40 degree in high $^{-1}$ and indigenous populations of Ethiopia. The average height of bird was $44.70 \mathrm{~cm}$ and the value ranged from 42.0 to $50.0 \mathrm{~cm}$ among the individuals. The body length of Aseel chicken measured in this study was ranging from 49.00 to 60.00 $\mathrm{cm}$ with the overall mean of $53.80 \mathrm{~cm}$. The perusal of literature revealed that the indigenous chickens of the Ethiopia had comparatively shorter bodies of 38.27 to $40.38 \mathrm{~cm}$ (Bekele et al., 2015) and $22.8 \mathrm{~cm}$ (Negassa et al., 2014).

\section{References}

Deneke. N., A. Melesse, and S. Banerjee. 2014. Phenotypic characterization of indigenous chicken populations in South eastern Oromia Regional State of Ethiopia. Animal Genetic Resources., 55:101-113.

Getachew. B., K. Kebede and N. Ameha. 2015. On-farm Phenotypic characterization of indigenous chicken and their production system in Bench Maji Zone, South Western Ethiopia. Sci. Technol. Arts Res. J., 4(1): 68-73

Nigussie. D., T. Dessie, Liesbeth H. van der Waaij and Johan A.M. van Arendonk. 2010. Morphological features of indigenous chicken populations of Ethiopia. Animal Genetic Resources., 46: 11-23.

Kumar P.G., R.R. Churchil, A. Jalaludeen, K. Narayanankutty, L. Joseph, A. Kannan and P. Anitha. 2013. A survey on village chicken production in Kerala state of India. World's Poult Sci. J., 69: 917-929.

Kumar, P.G., R. R. Churchil, A. Jalaludeen, K. Narayanankutty, P.A. Peethambaran, P.E. Praveena, B. Chacko and B. Ajithbabu. 2016. Egg production and certain behavioural characteristics and mortality pattern of indigenous chicken of India. Animal Genetic Resources, 59: 27-36

Rajkumar, U., S. Haunshi, C. Paswan, M.V.L.N. Raju, S.V. Rama Rao and R.N. Chatterjee. 2017. Characterization of indigenous Aseel chicken breed for morphological, growth, production, and meat composition traits from India. Poult Sci., 96: 2120-2126.

Singh D. P., 2001. Aseel of India. In: Souvenir, National Seminar on Appropriate poultry for adverse environment. Organized by Acharya 
N.G. Ranga Agricultural University and Project Directorate on Poultry, Hyderabad $11^{\text {th }}$ January 2001.

Singh D. P., 2009. Overview of existing breeds and issues of conserving indigenous breeds. In. Proc. Natl.
Workshop on synthesizing experiences in the promotion of backyard Poultry. Govt. of Andhra Pradesh, Hyderabad, India. Pp. 54-55.

\section{How to cite this article:}

Richard Churchil, R., J. Jamima, Yadav Sunil Machindra, P. Kanagaraju and Srinivasan, G. 2019. Qualitative and Morphometric Characters of Aseel Male Chicken. Int.J.Curr.Microbiol.App.Sci. 8(01): 1285-1289. doi: https://doi.org/10.20546/ijcmas.2019.801.136 